\title{
Relation of the Ankle Brachial Index (ABI) to left ventricular systolic function in patients with coronary artery disease
}

\author{
Mahasen M. Abd Al-Majeed* \\ Najeeb H. Mohammed** \\ Hilal B. Al Saffar***
}

\author{
MBChB, DDV \\ MBChB, MSc, DM, PhD \\ MBChB, FRCP, FACC
}

\begin{abstract}
:
Background: Atherosclerosis is a diffuse disease process, being present in one vascular bed predicts its presence in the others. Ankle -Brachial Pressure Index (ABI) is a simple index related to the extent of atherosclerosis in coronary and noncoronary arterial beds, reflecting generalized atherosclerosis.

Objectives: the aim of this study is to evaluate the relation of ABI to left ventricular systolic function using echocardiography in patients with coronary artery disease (CAD).

Patients and Methods: Sixty seven patients (67) with CAD of either sex (70\% males) with mean age $58 \pm$

J Fac Med Baghdad 2015; Vol.57, No.1 Received Aug. 2014 Accepted Sept.2014 6 years enrolled in this study, from December 2013 till May 2014; all were referred to the Iraqi Centre for Heart Disease (I.C.H.D.) for further evaluation and management. The ABI for each leg was calculated by dividing the lowest value of the ankle systolic blood pressure (SBP) (over both dorsalis pedis and posterior tibial arteries) by the highest value of either brachial SBP by using a Doppler ultrasound. The lower of the two values was used to define the patient ABI. The ejection fraction (EF) \% and fractional shortening (FS) $\%$ were determined by using trans-thoracic echocardiography. Participants were divided into two groups according to ABI results: Group I: 29 patients with abnormal low ABI $(\mathrm{ABI} \leq 0.90)$ with $\mathrm{ABI}$ mean of $0.79 \pm 0.12$ and Group II: 38 patients with normal $\mathrm{ABI}(0.9<\mathrm{ABI} \leq 1.30)$ with $\mathrm{ABI}$ mean of $1.03 \pm 0.10$ as a control group.

Results: There were no statistically significant differences in statistics between the two groups regarding risk factors for atherosclerosis. EF\% was significantly lower in group I than those in group II in such a way that the mean values of $\mathrm{EF} \%$ was $53.41 \pm 14.72$ for group I vs. $63.11 \pm 8.93$ for group II with the $\mathrm{p}$ value $=$ 0.003 . Also ABI is correlated with the severity of left ventricular systolic dysfunction.

Conclusion: $\mathrm{ABI}$ is a useful bedside clinical test that predicts and assess left ventricular systolic dysfunction in patients with coronary artery disease.

Keywords: Coronary artery disease - Ankle brachial index - Ejection Fraction.
\end{abstract}

Introduction:

Atherosclerosis is a disorder that comprises the development of focal atheroma, within the intima and inner portion of the media. As the disorder advances, the atheroma undergoes a variety of complications as calcification, internal hemorrhages, ulceration, and sometimes superimposed thrombosis (1). Coronary artery disease (CAD) is a narrowing of the vessels that supply blood and oxygen to the heart and it is most commonly due to atherosclerosis in about $99 \%$ of cases $(2,3)$.Studies found that the prevalence of coronary artery disease (CAD) forms up to $90 \%$ in patients with peripheral artery disease (PAD) (1). The ankle brachial index (ABI) is a simple noninvasive test, reflecting the ratio of the systolic blood pressure (SBP) in the ankle divided by SBP in the brachial artery.PAD is commonly assessed by the measurement of $\mathrm{ABI}$ and low ABI measurements $(\leq 0.90)$ have been studied as a marker of

* Dept. of Physiology, College of Medicine, Iraqi University.

**Dept. of Physiology, College of Medicine, Baghdad University.

***Dept. of Medicine, College of Medicine, Baghdad University.

Email:Dr._najeebalmously@yahoo.com atherosclerotic PAD for over 40 years $(4,5)$. Numerous studies have found low ABI values to be an independent predictor of cardiovascular events, including myocardial infarction, stroke, and mortality (6). Normal values generally range from $0.91-1.3$ (7). The ratio of ABI is $>1.0$ because the shape of the arterial waveform changes from the central aorta to the periphery, with the systolic blood pressure increasing at peripheral sites owing to arterial waveform reflection and summation (8) Although CAD is often accompanied by left ventricular (LV) systolic dysfunction (9), data relating ABI values to LV structural and functional abnormalities are sparse. Recently, low ABI values have been found to be associated with LV hypertrophy (10) a well-known risk factor for LV dysfunction and heart failure (11). Because left ventricular (LV) systolic function has been shown to influence arterial wave reflective properties (10), it is presumed that the ABI would reflect LV systolic function, as well atherosclerosis. Exact measurement of ventricular function in CAD patients has an important role in future treatment plans. Current study aim is to evaluate the relation of 
ABI to left ventricular systolic function by measuring ejection fraction and fractional shortening using echocardiography in patients with coronary artery disease.

\section{Patients and Methods:}

Sixty seven patients (67) of either sex (70\% males with mean age $58 \pm 6$ years) with coronary artery disease (CAD) as documented by coronary angiography enrolled in this study, from December 2013 till May 2014; all were referred to the Iraqi Centre for Heart Disease (I.C.H.D.) for diagnostic coronary angiography, percutaneous coronary intervention (PCI) or for coronary artery bypass graft (CABG). Inclusion criteria include patients with positive coronary angiography ( stenosis $\geq 50 \%$ for the left main stem and stenosis $\geq 70 \%$ for all other segments) while patients with normal coronary angiography, Predominant valvular heart diseases, patients with previous PCI and patients with previous CABG are excluded. All patients undergone determination of $\mathrm{ABI}$ and transthoracic echocardiographic studies in the same day. While the patient had rested in the supine position for at least 10 minutes whith the head and heels supported by the bed in a quiet room with comfortable temperature (21-23 ${ }^{\circ} \mathrm{C}$ ) to prevent vasoconstriction, the systolic blood pressure is measured at the right and left brachial, dorsalis pedis and posterior tibial arteries using a Doppler ultrasound probe (Huntleigh) held at 45 degrees angle over the arteries. The ABI for each leg was calculated by dividing the lowest value of either ankle SBP (dorsalis pedis or posterior tibial) by the highest value of either brachial SBP. The ABI is calculated for each leg separately, and the lower of the two values was used to define the patient ABI. Transthoracic echocardiography is performed for each patient involved in this study. The left ventricular (LV) dimensions were measured from $\mathrm{M}$ mode two-dimensional images according to the American Society of Echocardiography standards. while, the LV volumes were calculated according to the Teichholz M-mode formula and the ejection fraction was calculated as follows: $\mathrm{EF} \%=($ Stroke volume)/ (End diastolic volume) $\times 100 \%$ and the FS $\%=$ (LV internal dimension in diastole - $\mathrm{LV}$ internal dimension in systole)/ LV internal dimension in diastole $\times 100 \%$. Normal $\mathrm{EF} \%$ was defined as $\geq 55 \%$ whereas a normal $\mathrm{FS} \%$ lies in the range of $25-43 \%$ (12). Accordingly, participants were divided into two groups according to ABI results: Group I: 29 patients with abnormal low $\mathrm{ABI}(\mathrm{ABI} \leq 0.90)$ with $\mathrm{ABI}$ mean of $0.79 \pm 0.12$ and Group II: 38 patients with normal ABI $(0.9<$ $\mathrm{ABI} \leq 1.30$ ) with $\mathrm{ABI}$ mean of $1.03 \pm 0.10$ served as control group.

\section{Statistical Analysis:}

All data were coded and computerized analysis using the Statistical Package for Social Sciences (SPSS 13) program, the associations between discrete variables were measured using (chi square test), and the differences between continuous variables were measured using the ( $t$ test) and the analysis of variance (ANOVA) test. The Correlation coefficient was used to measure the association between the continuous variables, a logistic regression models were built to recognize the dependent and independent factors. $\mathrm{P}$ value $\leq 0.05$ was considered as a cutoff value for the level of significance. Consequently, the graphs were executed using SPSS while the tables were executed by using Microsoft Office word 2010.

\section{Results:}

The characteristics of the two groups: Group I; consisted of $29(43.28 \%)$ patients of either sex; 20 men and 9 women with a mean age of $58.93 \pm 6.52$ years with abnormal low ABI (ABI $\leq 0.90)$ with ABI mean $(0.79 \pm 0.12)$ and Group II; consisted of $38(56.72 \%)$ patients of either sex; 27 men and 11 women with a mean age of $58.93 \pm 7.85$ years with normal ABI $(0.9<\mathrm{ABI}$ $\leq 1.30)$ with $\mathrm{ABI}$ mean $(1.03 \pm 0.10)$. They are age and gender matched groups. Table (1) shows no significant difference in their demographic, anthropometric and clinical characteristics $(\mathrm{P}>0.05)$.

Table (1): Demographic, anthropometric and clinical data of studied groups.

\begin{tabular}{|c|c|c|c|}
\hline Variables & $\begin{array}{c}\text { Group } I \\
\mathrm{ABI} \leq 0.9 \\
\text { mean }=0.79 \pm 0.12 \\
\mathrm{n}=\mathbf{2 9}\end{array}$ & $\begin{array}{c}\text { Group II } \\
0.9<\mathrm{ABI} \leq 1.3 \\
\text { mean }=1.03 \pm 0.10 \\
\mathrm{n}=\mathbf{3 8}\end{array}$ & P value \\
\hline Age(years) & $58.93 \pm 6.52$ & $58.93 \pm 7.85$ & 0.315 \\
\hline BMI(Kg/m2) & $27.79 \pm 4.34$ & $27.03 \pm 4.50$ & 0.756 \\
\hline $\begin{array}{l}\text { Waist to hip } \\
\text { ratio(WHR) }\end{array}$ & $0.96 \pm 0.097$ & $0.95 \pm 0.078$ & 0.828 \\
\hline SBP(mmHg) & $137.24 \pm 21.70$ & $119.89 \pm 13.79$ & 0.097 \\
\hline DBP(mmHg) & $74.14 \pm 14.27$ & $73.71 \pm 9.54$ & 0.627 \\
\hline МАВР(mmHg) & $94.62 \pm 16.49$ & $87.82 \pm 15.17$ & 0.166 \\
\hline
\end{tabular}

- Data are expressed as mean $\pm \mathrm{SD}$.

- Significant whenever the $\mathrm{P}$ value is $\leq 0.05$.

- $\mathrm{BMI}=$ body mass index.

- $\mathrm{SBP}=$ systolic blood pressure.

- $\mathrm{DBP}=$ diastolic blood pressure.

- $\mathrm{MABP}=$ mean arterial blood pressure.

As shown in Table (2) there are no significant difference between the two groups regarding age, gender, smoking, accompanied comorbidities including hypertension and dyslipidemia $(\mathrm{P}>0.05)$. However, it shown statistically significant increase in the percentage of diabetes mellitus in 
Group I when compared to Group II (55.2\% and 34.2\% with p value 0.001 ) both of them uncontrolled diabetes to the time of examination in which the mean fasting blood sugar are $180 \pm$ $48 \mathrm{mg} / \mathrm{dL}$ for group I and $145 \pm 46 \mathrm{mg} / \mathrm{dL}$ for group II.

Table (2): Risk factors distribution among the studied groups.

\begin{tabular}{|c|c|c|c|c|c|}
\hline \multirow[t]{2}{*}{ Variables } & \multicolumn{2}{|c|}{$\begin{array}{c}\text { Group } I \\
\mathrm{ABI} \leq 0.9 \\
\text { mean }=0.79 \pm 0.12 \\
\mathrm{n}=29\end{array}$} & \multicolumn{2}{|c|}{$\begin{array}{c}\text { Group II } \\
0.9<\mathrm{ABI} \leq 1.3 \\
\text { mean }=1.03 \pm 0.10 \\
\mathrm{n}=\mathbf{3 8}\end{array}$} & \multirow[t]{2}{*}{ P value } \\
\hline & No. & $(\%)$ & No. & $(\%)$ & \\
\hline Male & 20 & 69.0 & 27 & 71.1 & 0.555 \\
\hline Female & 9 & 31.0 & 11 & 28.9 & 0.555 \\
\hline Smoking & 13 & 44.8 & 18 & 47.4 & 0.838 \\
\hline Hyperlipidemia & 22 & 75.9 & 31 & 81.6 & 0.587 \\
\hline Diabetes mellitus & 16 & 55.2 & 13 & 34.2 & 0.001 \\
\hline Hypertension & 18 & 62.1 & 21 & 55.3 & 0.161 \\
\hline
\end{tabular}

Regarding the parameters that reflect left ventricular systolic function, Table (3) and Figure (1) shown a statistically significant ( $p$ value $\leq 0.05$ ) decreases in the left ventricular EF\% for Group I when compared to Group II in such a way that the mean values of $\mathrm{EF} \%$ were $(53.41 \pm 14.72$ vs. $63.11 \pm 8.93)$ as shown in.

Table 3: Left ventricle systolic function parameters among the studied groups.

\begin{tabular}{|c|c|c|c|}
\hline $\begin{array}{l}\text { Systolic } \\
\text { function }\end{array}$ & $\begin{array}{c}\text { Group I } \\
\mathrm{ABI} \leq \mathbf{0 . 9} \\
\text { mean }=0.79 \pm 0.12 \\
\mathrm{n}=29\end{array}$ & $\begin{array}{c}\text { Group II } \\
0.9<\mathrm{ABI} \leq 1.3 \\
\text { mean }=1.03 \pm 0.10 \\
\mathrm{n}=38\end{array}$ & P Value \\
\hline EF\% & $53.41 \pm 14.72$ & $63.11 \pm 8.93$ & 0.003 \\
\hline FS\% & $28.62 \pm 9.96$ & $33.82 \pm 7.39$ & 0.035 \\
\hline
\end{tabular}

- Data are expressed as mean $\pm \mathrm{SD}$.

- Significant whenever the P value is $\leq 0.05$.

- $\mathrm{EF}=$ ejection fraction.

- $\mathrm{FS}=$ fractional shortening.

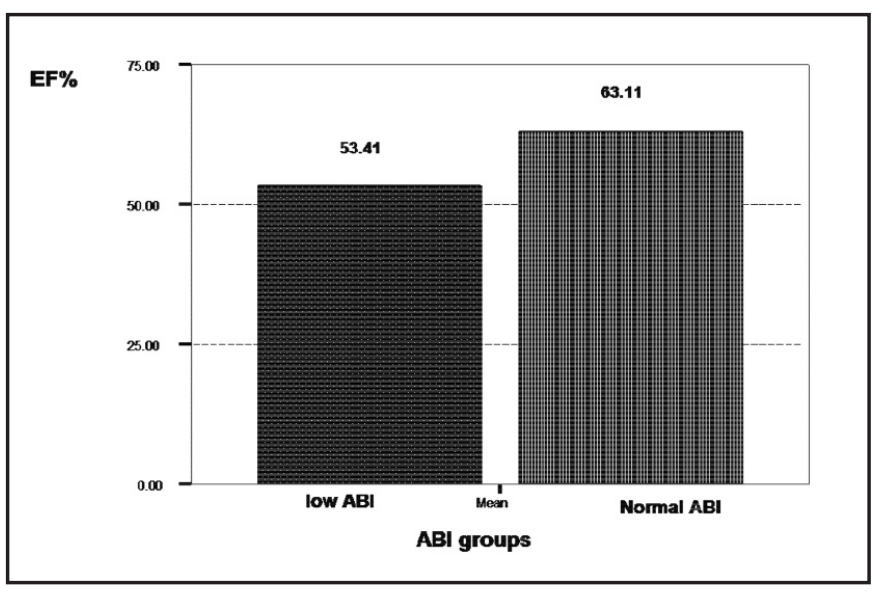

Figure (1): Left ventricular EF\% distribution among the studied groups.

When the left ventricular systolic dysfunction forms were considered as shown in table (4), higher $\%(34.5 \%)$ of subjects within Group I with low ABI developed mild form while the higher $\%(86.8 \%)$ of subjects within Group II with normal ABI developed normal systolic function form; so the result of the study showed that there were more sever forms of systolic dysfunction in the low ABI group. There were statistically nonsignificant $(\mathrm{P}$ value $>0.05)$ positive linear correlation between $\mathrm{EF} \%$ and $\mathrm{ABI}$ in low ABI Group (Group I) $\mathrm{r}=0.01$.

Table (4): Forms of Left ventricle systolic dysfunction among the studied groups.

\begin{tabular}{|c|c|c|c|}
\hline $\begin{array}{l}\text { Systolic } \\
\text { function } \\
\text { Forms }\end{array}$ & $\begin{array}{c}\text { Group } \mathrm{I} \\
\mathrm{ABI} \leq 0.9 \\
\text { mean }=0.79 \pm 0.12 \\
\mathrm{n}=29\end{array}$ & $\begin{array}{c}\text { Group II } \\
0.9<\mathrm{ABI} \leq 1.3 \\
\text { mean }=1.03 \pm 0.10 \\
\mathrm{n}=38\end{array}$ & P Value \\
\hline & No.(\%) & No. (\%) & \\
\hline Normal & $33.9 \%)) 11$ & $86.8 \%)) 33$ & \multirow{4}{*}{0.000} \\
\hline Mild & $34.5 \%)) 10$ & $(10.5 \%)) 4$ & \\
\hline Moderate & $24.1 \%)) 7$ & $2.6 \%)) 1$ & \\
\hline Sever & $3.4 \%)) 1$ & $0(\%)$ & \\
\hline
\end{tabular}

\section{Discussion:}

In this study the relatively wide range distribution of the age for the studied groups (40-70years) may indicate the coronary artery disease almost distributed from middle to elderly age which is the same finding stated by Curtis M. Rimmerman(13) who stated that the age prevalence of CAD were $>30$ years or $<69$ years. Also in this study showed that the higher percentage of male involvement among the studied groups the male percentage being higher than female in the low and normal ABI groups (69.0\% and $71.1 \%$ respectively). These values seem to be approximately similar to the values in other studies (14, 
15) whereas Abbasnezhad, et al. stated that the prevalence of abnormal ABI was similar in both sexes (8) while others report that low $\mathrm{ABI}$ is related to female gender $(16,17)$. This gender differences may be due to ethnical differences and it seems that more studies with larger sample size are needed for more conclusive results. The study showed higher percentage of diabetes mellitus among low ABI group than in the normal ABI group, this was the same result found by Zhang, et al and Resnick, et al. $(18,19)$. This can be explained by the fact that hyperglycemia is metabolic abnormality that leads to dysfunction of multiple cells which increase the likelihood of developing atherosclerosis in multiple beds including CAD and PAD. Regarding the parameters that reflect left ventricular systolic function this study showed that statistically significant decreasing in the percentage of EF in the low ABI group when compared with the normal ABI group and more deterioration in function was noted as the ABI decreases below 0.9, this is in agreement with Rizvi, et al. who conducted a study on 175 patients in USA referred for ABI determination, the mean LVEF increased from the low, to normal ABI groups $(43+/-$ $13 \%$ vs. $51+/-12 \%$ respectively with $\mathrm{P}<0.01$ ) which support the hypothesis that $\mathrm{ABI}$ could be an indicator of CAD severity and showed that the ABI is influenced by LV systolic function, independent of coronary disease (11). Like-wise Ward, et al. studied 204 patients with symptomatic PAD found that LVEF less than $55 \%$ among patients with low $\mathrm{ABI}$ is more common than normal ABI (20). Also in the study by Santo Signorelli, et al. $\mathrm{LVEF}<50 \%$ had higher prevalence in patients with $\mathrm{ABI} \leq 0.9$ (21a). Similarly Zhang, et al. (18) study showed that the EF\% was significantly lower in the low ABI group (53.92\%) than that in normal ABI group 69.74\%). Amer, et al. studied 100 patients with ischemic heart disease and stated that EF was lowest in cases $>70$ years $(46.84 \pm 9.82)$ and he stated that the explanation is that LV systolic function has been shown to influence arterial wave reflective properties (22). Also Abbasnezhada, et al. conducted a study on diabetic patient and non-diabetic patients referred for ABI determination that had their LVEF determined using trans-thoracic echocardiography and showed the percentage of patients with LVEF below 50\% was higher in low ABI group than in patients with the normal $\mathrm{ABI}$ and concluding that ABI would be influenced by LVEF in diabetics and non-diabetics. However, in the previous two studies patients were not known to have $\operatorname{CAD}(8,23)$. But our study doesn't agree with Thatipelli, et al. who studied 395 patients referred for dobutamin stress echocardiography and $\mathrm{ABI}$ determination and observed that there was no relation between $\mathrm{ABI}$ and left ventricle wall motion index score at rest or after stress(24)and Maldonado, et al. found ABI to be inversely correlated with LV mass and systolic function (25). These different findings between these studies could be probably due to differences in population under study in each research and method of left ventricle function and ejection fraction measurement. Therefore, it seems that more studies with larger sample size are needed for more conclusive results. Although the mechanism of relation between ABI and LVEF remain uncertain, $\mathrm{CAD}$ is unlikely to be a confounding factor. Maldonado, et al. found that the ABI values directly related to LV functional and arterial stiffness index (24). These results suggested that $\mathrm{ABI}$ reflects functional and structural properties related to ventriculo-arterial coupling. One possible explanation is that LV systolic function has been shown to influence arterial wave reflective properties (10).

\section{Conclusion:}

Abnormal ABI is associated with left ventricular systolic dysfunction. Accordingly, ABI is a useful bedside clinical test that predicts and assess left ventricular systolic dysfunction in patients with CAD.

\section{Authors contributions:}

Study conception, Critical revision and design: Najeeb Hassan Mohammed and Hilal Bahjet Al Saffar (supervisors).

Acquisition of data analysis, Drafting of manuscript and Interpretation of data : Mahasen Mohammed Abd Al-Majeed, Najeeb Hassan Mohammed and Hilal B. Al Saffar.

\section{References:}

1. Murabito JM., Evans JC. and Nieto K.: Prevalence and clinical correlates of peripheral arterial disease in the Framingham Offspring Study. Am Heart J. 2002; 143:961965.

2. Homoud M.K.: Coronary Artery Disease. Tufts-New England Medical Center. Spring 2008.

3. Malcoma TG. and McMahanb CA.: Associations of Arterial Tissue Lipids with Coronary Heart Disease Risk Factors in Young People. Atherosclerosis Journal, 2009; 203(2); $515-$ 521.

4. Stoffers D., Marin DT. Dermott MM., et al.: Measurement and Interpretation of the Ankle-Brachial Index. Circulation November 16, 2012; 126:2890-2909.

5. Grenon SM., Gagnon J. and Hsiang Y.: Ankle-Brachial Index for Assessment of Peripheral Arterial Disease. $N$ Engl J Med., 2009; 361:40.

6. Fowkes FG., Murray GD., Butcher I., et al.: Ankle brachial index combined with Framingham Risk Score to predict cardiovascular events and mortality: a meta-analysis.JAMA., 2008; 300(2):197-208.

7. Al-Qaisi, Nott DM., King DH. and Kaddoura S.: Ankle Brachial Pressure Index (ABPI): An update for practitioners. Dove Medical Press Ltd. Vascular Health and Risk Management 2009; 5:833-841.

8. Abbasnezhad M., Asgarzadeh AA., Aslanabadib H. and 
Habibzadehc A.: Relation of Ankle Brachial Index to Left Ventricular Ejection Fraction in non-Diabetic Patients. Journal of cardiovascular and thoracic research, 2011; (4), 109-112. (IVSL)

9. Morillas P., Cordero A., Bertomeu V., et al.: Prognostic value of low ankle-brachial index in patients with hypertension and acute coronary syndromes. J Hypertens., 2009; 27(2):341347.

10. Weber T., Auer J., Lamm G., O'Rourke MF. and Eber B.: Arterial stiffness, central blood pressures, and wave reflections in cardiomyopathy-implications for risk stratification. J Card Fail., 2007;13(5):353-359.

11. Rizvi S., Kamran H., Salciccioli L., Saiful F., Lafferty J. and Lazar JM.: Relation of the ankle brachial index to left ventricular ejection fraction. Am J Cardiol., 2010;105(1):129132. (IVSL)

12. Peterson LR., Waggoner AD., Schechtman KB., et al.: Alterations in left ventricular structure and function in young healthy obese women, Assessment by echocardiography and tissue Doppler imaging. J Am Coll Cardiol., 2004;43(8):13991404.

13. Curtis M. Rimmerman: Coronary Artery Disease. Cleveland clinic., February 2013.

14a. Hilal B. Al Saffar, Haider J. Al Ghizzi and Shakir M. Muhammed: The Ankle- Brachial Pressure Index AS A Predictor of Coronary Artery Disease Severity. Fac Med Baghdad, 2009; Vol. 51, No.3. (IVSL)

15. Price JF., Stewart MC., Douglas AF., Murray GD. and Fowkes GF.: Frequency of a low ankle brachial index in the general population by age, sex and deprivation: crosssectional survey of 28,980 men and women. Eur J Cardiovasc Prev Rehabil., 2008;15:370-5.

16. Luo YY., Li J., Xin Y., Zheng LQ., Yu JM. and Hu DY.: Risk factors of peripheral arterial disease and relationship between low ankle brachial index and mortality from all-cause and cardiovascular disease in Chinese patients with hypertension. J Hum Hypertens., 2007;21:461-6.

17. Sadrzadeh Rafie AH., Stefanick ML., Sims ST., et al.: Sex differences in the prevalence of peripheral artery disease in patients undergoing coronary catheterization. Vasc Med., 2010; 15(6): 443-50.

18. Zhang Xiao-dong, LI Yi, Dong Ying-jie, Wang Hui-qun, LI Xu-liang and Zheng Jia-lin.: Correlation between Anklebrachial Index with Echocardiography and the Coronary Atherosclerosis Lesions in Patients with Coronary Heart Disease. Journal of Kunming Medical University, 2009-05

19. Resnick HE., Lindsay RS., McDermott MM., Devereux RB., Jones KL. and Fabsitz : Relationship of High and Low Ankle Brachial Index to All-Cause and Cardiovascular Disease Mortality The Strong Heart Study. Circulation, 2004;109:733739.
20. Ward RP., Goonewardena SN., Lammertin G. and Lang RM.: Comparison of the frequency of abnormal cardiac findings by echocardiography in patients with and without peripheral arterial disease. Am J Cardiol., 2007;99:499-503. 21. Santo Signorelli S., Anzaldi M., Fiore V., et al.: Study on unrecognized peripheral arterial disease (PAD) by anklel brachial index and arterial comorbidity in Catania, Sicily, Italy. Angiology 2010;61: 524-9.

22. Amer M., Tawfik H., Maamoun M. and Abd Elmoteleb AM.: Relationship between Peripheral Artery Disease and Cardiac Function in Elderly Patients with Ischemic Heart Disease. The Egyptian Journal of Hospital Medicine, April 2013; 51: 285-288. (IVSL)

23. Abbasnezhada M., Asgarzadehb AA., Aslanabadib H. and Habibzadehc A.: Relation of Ankle Brachial Index to Left Ventricular Ejection Fraction in Diabetic Patients. Journal of Endocrinology and Metabolism, December 2012; 2(6): 228231. (IVSL)

24. Thatipelli MR., Pellikka PA., McBane RD., et al.: Prognostic value of anklebrachial index and dobutamine stress echocardiography for cardiovascular morbidity and all-cause mortality in patients with peripheral arterial disease. J Vasc Surg., 2007; 46:62-70.

25. Maldonado J., Pereira T., Resende M., Simões D. and Carvalho M.: Usefulness of the ankle-brachial index in assessing vascular function in normal individuals. Rev Port Cardiol 2008;27:465-76. 